\title{
Cortés Vázquez, José Antonio (2013): Naturalezas en conflicto. Conservación ambiental y enfrentamiento social en el Parque Natural Cabo de Gata-Níjar. Valencia: Germanía-Asociación Valenciana de Antropología. 323 pp. ISBN: 978-84-15660-29-3.
}

Cuando Pedro Molina y yo estuvimos haciendo trabajo de campo en el municipio de Nijar entre 1983 y 1989 y luego realizando estancias de más cortas duración hasta 1996 (fechas y referencias bibliográficas), asistimos al paso de un modo de subsistencia que llamamos el complejo agro-pastoril basado esencialmente en la agricultura de secano, el pastoreo extensiva, la pesca artesanal de litoral y la recolección de plantas de uso comercial o industrial, hacia una producción agrícola de alto rendimiento orientada hacia el mercado, fruto de sucesivas innovaciones tecnológicas. En el contexto de nuestra investigación, la declaración institucional de buena parte del municipio como parque natural (Parque natural de Cabo de Gata-Nijar) que se plasmó en 1987 pero cuyos efectos prácticos se hicieron sentir algunos años más tarde, actúo como un verdadero acontecimiento crisis ${ }^{1}$, es decir como un revelador de conflictos latentes y sobre todo como anunciador de un cambio de paradigma en los objetivos y en las reglas que hasta entonces regían las relaciones sociales a escala local. Para el etnógrafo, este tipo de acontecimiento suele representar un momento particularmente privilegiado porque tiene la oportunidad de observar como se polarizan intereses divergentes y como se van formando grupos de presión que recortan y redistribuyen con nuevas líneas divisorias los diferentes sectores sociales implicados. Esto nos ocurrió al final de nuestra experiencia de campo, reorientando nuestros primeros objetivos hacia otras metas. Campo de Nijar escapaba así al destino canónico de objeto de estudio y de unidad metodológica que le habíamos asignado en un principio y se desvelaba como espacio "vivo" atravesado por dinámicas que, si bien se presentaban fundamentalmente distintas de las del pasado, anunciaban su proyección futura, mediante la re ordenación de las posiciones de los diferentes protagonistas como si de un calidoscopio se tratase pero, esta vez, en una escala que trascendía los linderos del Parque institucionalmente concebidos. Sin embargo, en aquella época teníamos que poner un punto final a lo que había sido una larga, dura y sin embargo apasionante investigación. Era hora que otras miradas etnográficas tomasen el relevo y pudieran analizar, desde los últimos avances de la reflexión

${ }^{1}$ Cf. al respecto el artículo de Bensa, A. y Fassin, E. (2002): "Les sciences sociales face à l'événement", Terrain, 38: 5-20; así como el libro de Grossetti, M. (2004): Sociologie de l'imprévisible. Dynamiques de l'activité et des formes sociales. París: PUF. antropológica sobre la interacción entre la naturaleza y la cultura, los procesos que la gestión del parque había desencadenado y la nueva vocación que, desde las instituciones competentes, se le asignaba, el modelo de desarrollo rural respetuoso del entorno tomaba el relevo del desarrollo agrario productivista.

El libro de José Antonio Cortés, Naturalezas en conflicto, ha cumplido perfectamente este cometido y ha permitido que esta región almeriense siga siendo un hito en el debate ecológico, como lo fue antaño en las perspectivas desarrollistas de los años 70 y 80 y como se supone que lo será en breve, con la mercantilización del carácter "virgen" de algunos de sus paisajes por multinacionales turísticas.

Muy bien documentado y de lectura amena a pesar de su rigor científico, este libro inicia lo que tendría que ser un estado de la cuestión sobre los espacios protegidos en un momento de crisis como él que vivimos y de reestructuración de un capitalismo globalizado agresivo. Es por lo tanto de extrema actualidad. Pero aquí me limitaré a subrayar los aspectos que me parecen más valiosos en cuanto a la antropología del espacio se refiere.

En primer lugar, desmonta minuciosamente el mecanismo según el cual un determinado entorno transformado a lo largo de la historia por sus moradores en busca de subsistencia se convierte de repente ${ }^{2}$ en espacio "natural" necesitado de protección por obra y gracia de la administración pública. En unas brillantes páginas de introducción y desde un enfoque crítico y epistemológico, el autor desconstruye la noción de "natural", basada en un dualismo ideológico (lo natural opuesto a lo no natural, es decir artificial versus contra-natura) y en una concepción ontológica del paisaje que lleva a privilegiar medidas conservacionistas, hasta el punto que el único uso admitido sea él de su contemplación visual, concepción que evidentemente se opone a las diversas concepciones locales o "émicas" de las diferentes categorías de productores u de otros residentes instalados dentro del parque o en sus inmediaciones.

En segundo lugar, pone de relieve como se instaura, desde las instancias del poder, el proceso de apropiación simbólica que antecede el proceso de

\footnotetext{
2 Esto es aparente: la declaración administrativa de Parque natural fue precedida por años de sordas luchas entre residentes ocasionales procedentes de Almería o de Madrid, la población local y los diferentes niveles de la administración, según su orientación política.
} 
apropiación real, bajo forma de gestión institucional. El carácter único de algunos de los ecosistemas de la zona científicamente comprobados, la singularidad de los paisajes desérticos y el descubrimiento de la belleza de algunas partes del litoral, hasta ahora de muy difícil acceso, están resaltados como un patrimonio colectivo cuya excepcionalidad requiere reconocimiento público pero cuya fragilidad frente a las crecientes presiones de los productores requiere medidas de protección. Una vez fijadas las fronteras entre la zona que se quiera proteger y las áreas de su entorno, mediante la recalificación de sus características y de sus nuevos usos -que reviste la forma de una gestión racional- se va limitando progresivamente, hasta su prohibición total en determinadas áreas, todas las prácticas consideradas incompatibles con la nueva definición de patrimonio "natural", a la cual se añaden elementos culturales esencialmente arquitectónicos y artesanales- que vienen a conferir una legitimidad suplementaria al Parque mediante el recurso a la historia cuidadosamente depurada de todos los elementos pasados negativos. Otra función más pragmática, destinada a sacar partido de la función estética y contemplativa se va imponiendo paulatinamente. La administración andaluza busca promover actuaciones de desarrollo sostenible mediante un turismo rural de calidad en las zonas del litoral en donde hay ya asentamientos, como en la Isleta del Moro o en Rodalquilar, para mencionar los más significativos. Se trata por consiguiente de un proceso a la vez incluyente y excluyente según la categoría de población y el tipo de actividad a la que se dedica. El discurso institucional plasmado en decisiones $y$ actuaciones cada vez más precisas y restrictivas contrasta con los testimonios de los otros colectivos involucrados y con sus respectivas representaciones de un entorno que consideran como exclusivamente de ellos y donde se sienten arbitrariamente desposeídos a pesar de los sucesivos decretos que constituyen el Parque como tal y de las campañas de sensibilización a favor de la preservación del medioambiente que en todos estos años se han multiplicado en toda en España. Sin embargo, estas representaciones no son simplemente respuestas subjetivas y oposición cerril y desfasada de un sector de población local con pocos o nulos conocimientos del impacto de sus actividades productivas sobre el entorno y mal informado del cambio de la opinión pública al respecto, como se tiende demasiado a menudo a considerarlas, sino que se han forjado a partir del abanico de prácticas productivas que se fueron desarrollando y modificándose a través de los siglos, y particularmente en las cuatro últimas décadas con la implantación de nuevas técnicas agrícolas. Los cultivos en enarenados sustituidos posteriormente por la instalación de invernaderos, la adopción, primero del riego por aspersión y, luego del gota a gota, la utilización de semillas nuevas adaptadas a las condiciones climatológicas y, finalmente, la utilización de productos fitosanitarios que les permiten proteger sus cosechas de las plagas y adelantar su recogida dentro del ciclo agrícola, forman su propio patrimonio, tanto más apreciado y reivindicado que sin todas estas iniciativas, ellos y sus familias hubieran sido abocados a una existencia de miseria y forzados a exiliarse como sus padres, antaño, y buscarse la vida a otra parte. Por ello, se consideran los verdaderos defensores del entorno legitimados por todas las acciones productivas que, según ellos, le dan "vida". La poca sensibilidad que manifiestan a los destrozos que acometen sobre el paisaje (mar de plástico entre dos cerros, desechos de invernaderos entre los bancales de acceso en verano) se explica por considerarse los primeros, ellos o sus padres, que fueron capaces de transformar el desierto en un vergel. Aquella "tierra maldita", "aquella zona desgraciada abandonada, de la mano de Dios", según las palabras de los agricultores o de los pastores que habíamos recogido al inicio de nuestro trabajo de campo se ha convertido también para ellos en un entorno que defender y con el cual se identifican.

En tercer lugar, y siempre dentro del enfoque de la antropología del espacio, el estudio de los conflictos en torno a los que se han consolidado varias concepciones enfrentadas del territorio introduce en el libro, de forma oportuna la dimensión política y social necesaria a su comprensión. Las decisiones en torno a la gestión del parque, por ejemplo, la interdicción de instalar invernaderos para los agricultores cuyas propiedades están dentro de su ámbito o la limitación de las áreas marinas destinadas a la acuicultura denotan una subordinación para con los que "tienen el poder" que no hace sino recordar la antigua dependencia económica y social de los cortijeros de secano para con "los pudientes" es decir la desigualdad entre las familias que poseían grandes extensiones de tierras que no cultivaban ellos mismos y los aparceros o propietarios minifundistas que debían emplearse en las minas de los alrededores para malvivir. Más recientemente, tal como nos lo describe muy bien el autor, han aparecido nuevas líneas de fracturas, o bien internas a los colectivos de pobladores o bien entre los responsables locales y los gestionarios del parque que reproducen oposiciones que encontramos a escala nacional en el seno mismo de los partidos políticos entre quienes están a favor de un desarrollo sin límite, y quienes defienden la sostenibilidad de las acciones humanas. Para más precisión, los responsables municipales de Carboneras y Nijar en la época de la investigación de José Antonio Cortés se manifiestan a favor de un turismo de masas absolutamente inadaptado a la zona, debido a los menguantes recursos en agua. Así declara el alcalde de Nijar ante el estupor de los presentes. "Nijar no va a ser el único municipio español sin urbanizaciones turísticas y campos de golfo". Frase que, por su cortedad y falta de miras, no merece comentario. Solamente añadir que con la aparición de marcas extranjeras de fomento turístico que empiezan a interesarse a los rincones aún protegidos del parque, los supuestos beneficios de la promoción turística aquellos "dineritos" que dejan los veraneantes- en su 
gran mayoría, no irán a parar en las cajas municipales o en las de los comerciantes, sino que irán a "paraísos" de otra índole, y para hablar en latino paladino, a paraísos fiscales.

Acabaré diciendo que, además de sus indudable calidad científica y de la seriedad de su análisis, el libro de José Antonio Cortés Vásquez es de los pocos estudios del territorio que nos deja con ganas de seguir el relato de su evolución y saber, entre las fuerzas en presencia, en cada núcleo o barriada, como en cada trozo de terruño, sometido a protección o libre de explotación, cuales van a ser las que impondrán su modelo. El futuro es imprevisible, tanto más hoy en día con la crisis económica y su carácter global; pero podemos emitir un solo deseo: que ningún modelo prevalezca sobre el otro y que los municipios en los que se extienden el Parque sigan ofreciendo esta variedad de estrategias y de actividades que, según el área, ofrecen el recurso más adaptado a sus características para que se establezca entre todas un desarrollo controlado y harmonioso en que los consumidores del paisaje y los productores del mismo compaginen sus puntos de vista y coordinen sus respuestas a los desafíos por venir y sobre todo frente a la rapacidad de las grandes corporaciones multinacionales.

Danielle Provansal

Universitat de Barcelona, España dprovansal@ub.edu

Recibida: 22-01-2015

Aceptada: 12-03-2015

(c) (1) (3) 